Harrison, T. Manabe, M. Mietus, V. Swail, and S. Worley, 2004: The Second JCOMM Workshop on Advances in Marine Climatology (CLIMAR-II). WMO Bulletin, 53(2), 157-159.

WMO, 2003: Proceedings of CLIMAR99-WMO Workshop on Advances in Marine Climatology, Vancouver,
Canada, 1999, JCOMM Technical Report No. 13-CDROM.

Worley, S.J., S.D. Woodruff, R.W. Reynolds, S.J. Lubker, and N. Lott, 2005: ICOADS Release 2.1 data and products. Int. J. Climatol., 25, 823-842.

\title{
Report of the CLIVAR/00PC/G00S/Argo/CPPS Workshop on the South Pacific
}

\section{A. Caltabiano, ICPO}

National Oceanography Centre, Southampton, UK, email: icpo@noc.soton.ac.uk

What drives decadal variability in the South Pacific and to what extent can it be predicted? What fraction of decadal variability in the South Pacific is connected with ENSO? What factors influence the ocean/atmosphere interactions that drive changes in the subtropical cell? Is the observing system in the South Pacific adequate in monitoring oceanic and atmospheric features in the region? These were some of the questions addressed at the CLIVAR/OOPC/ GOOS/Argo/CPPS workshop on the South Pacific, held at the University of Concepción (UdeC), Chile, on 11-14 October 2005. The workshop had a very good attendance with 59 participants from 13 different countries, and was structured around fours sessions on Climate, Regional Impacts, Prediction and Predictability, and the Observing System. There was also a special session dedicated to the Argo Programme, and the impact it has had on monitoring the South Pacific.

One of the issues discussed relates to the air-sea interaction in the South Pacific, the need to examine this and its importance in underpinning statistical and dynamical forecast systems. This is an area where collaboration among CLIVAR's Pacific Panel, the Variability of the American Monsoon System (VAMOS) Panel, and the Working Group on Seasonal to Interannual Prediction (WGSIP) is desirable, to address, for example, the inter-relationships between tropical and Central South Pacific (CSP) SSTs and atmospheric changes over South America.

Two particular process studies in the Pacific area of great relevance to the South Pacific were presented. The first was the Pacific Upwelling and Mixing Physics (PUMP), which is being organized under US CLIVAR and is designed to improve the understanding of the variety of mechanisms that connect the thermocline to the surface in the equatorial Pacific cold tongue. Its goal is to observe and understand the interaction of upwelling and mixing with each other and with the larger-scale equatorial current system. The outcome of PUMP will be advancements in our ability to diagnose and model both the mean state of the coupled climate system in the tropics and its interannual and interdecadal variability. The second study was the Southwest Pacific Circulation and climate Experiment (SPICE).SPICE is aimed at a regional study of (i) bifurcation of the south equatorial current on the coast of Australia, (ii) the role of the east Australia current for the region, (iii) circulation in the North Coral Sea and includes a module on impacts and outreach. Both projects are still in the planning stages but were strongly encouraged to continue to pursue funding due to their importance for the South Pacific region and our understanding of ocean processes more generally.
Argo was discussed at considerable length. It was noted that there are considerable gaps in the current deployment for the South Pacific but those areas are being targeted for deployments by the US Argo program. The University of Concepción presently has 30 profiling floats in their inventory, some of which include dissolved oxygen sensors. Because the areas targeted by UdeC might have some overlap with the ones targeted by US, it was noted that a close interaction between those involved, with oversight by the Argo Program, was needed. Other deployment strategies were discussed and offers were made by representatives of Peru, Chile Ecuador and Colombia to assist with deployments for the completion of the global array.

All the other components of the observing system in the South Pacific were reviewed, with some important contributions on the efforts of the Pacific Island GCOS, and on data mining and data management. Considerable discussion also centred on the utility of gliders equipped with CTDs to sample the strong currents in the coastal zone. This discussion also noted that Argo is not very well suited to monitoring flow in boundary currents, but gliders are ideally suited. Gliders are poorly suited to sampling many locations in distant parts of the ocean, so there appears to be complementary features between these two systems.

It was also noted that the VAMOS Ocean-CloudAtmosphere-Land Study (VOCALS), which is presently in the planning stages of its field mission, will certainly provide a better understanding of the southeastern Pacific (SEP) coupled ocean-atmosphere-land system, on diurnal to interannual timescales. However, it was felt that VOCALS is very much focused on the marine boundary layer and clouds, therefore there is a strong need for a more sustained and coordinated effort to improve the monitoring of the eastern boundary current in the Southeastern Pacific. It was recommended that a small group could lead the task in gathering information on all the existing oceanographic observations in this region, to consider if there is a need of an additional sustained program that would enable a long term study of the eastern boundary current's impact on the South American continent.

The organising committee is very grateful to all the support provided by WCRP, US CLIVAR, GOOS/OOPC and Argo, which enabled key participants to attend the workshop. It also would like to thank the local support from the Center for Oceanographic Research in the Eastern South Pacific (COPAS), and the Department of Geophysics (DGEO) of the Faculty of Physical Sciences and Mathematics, University of Concepción. Presentations from the workshop can be found at: www.clivar.org/organization/pacific/implementation/ south_pac_workshop/south_pac.html 